\title{
Cost of Diabetic Foot Ulcer Management in China: A 7-Year Single-Center Retrospective Review
}

This article was published in the following Dove Press journal: Diabetes, Metabolic Syndrome and Obesity: Targets and Therapy

\author{
Qingwei Lu (D)' \\ Jun Wang' \\ Xiaolu Wei ${ }^{2}$ \\ Gang Wang' \\ Yang $X u^{\prime}$ \\ Zengzhen Lu' \\ Peng Liu' \\ 'Department of Ulcers and Peripheral \\ Vascular Surgery, First Teaching Hospital \\ of Tianjin University of Traditional \\ Chinese Medicine, Tianjin 300193, \\ People's Republic of China; ${ }^{2}$ School of \\ Integrated Traditional Chinese and \\ Western Medicine, Binzhou Medical \\ University, Yantai 264003, People's \\ Republic of China
}

Background: The cost of care for diabetic foot ulcers has became a global economic burden. The study aimed to analyze diabetic foot ulcer cost changes over time and to identify factors associated with these variables, so as to strengthen and improve the management of diabetic foot ulcers.

Methods: We retrospectively analyzed the data in the electronic medical record system of our wound treatment center. The homepage of the system was queried using the national clinical version 2.0 disease diagnosis code (ICD-10), the data of patient's basic information were exported. Through the statistics and analysis of these data, the socioeconomic changes and possible risk factors of diabetic foot ulcers management in recent years were obtained. Results: There were 3654 patients included in the study, an average of 522 per year. The total cost per patient increased from $¥ 15,535.58$ in 2014 to $¥ 42,040.60$ in 2020 , with an average of $¥ 21,826.91$. The average length of stay between 14.29 days and 31.4 days from 2014 to 2020, with an average of 18.10 days. Besides, the average incidence of peripheral arterial disease in diabetic foot ulcers patients admitted was as high as $81.9 \%$, and the average amputation rate was $9.9 \%$. The study reflected the total cost and length of stay of diabetic foot patients increased significantly from 2014 to 2020, which were related to age ( $>85$ years), gender (male), peripheral arterial disease, amputation $(\mathrm{P}<0.05)$.

Conclusion: A heavy cost from diabetic foot ulcers and its complications was significantly increased yearly, which was related to older age, co-morbidity, amputation and duration of hospitalization. The prevention and treatment of diabetic foot ulcers have a long way to go, early comprehensive prevention and multi-disciplinary cooperation may still be an effective way.

Keywords: diabetic foot ulcers, cost, socioeconomic, retrospective analysis, electronic medical record system, multi-disciplinary

\section{Introduction}

Diabetic foot (DF) is a kind of disease related to neuropathy and/or peripheral arterial disorder of the lower extremities and with infection, ulceration, and destruction of deep tissues in diabetic patients, as a result of the interaction of factors induced by sustained and uncontrolled hyperglycemia. Foot ulceration is the most frequently recognized complication. ${ }^{1,2}$ Complications of diabetes that affect the lower extremities are common, complex, and costly. The number of diabetic patients in the world is increasing dramatically year by year, and the prevalence of diabetic mellitus (DM) is also on the rise. ${ }^{3}$ The World Health Organization has

School of Integrated Traditional Chinese and Western Medicine, Binzhou Medical University, Yantai 264003, People's

Republic of China

Email weixiaolu0416@163.com 
reported that the estimated number of patients with diabetes was nearly 425 million in 2017, consequently, increasing the number of diabetes-related complications. ${ }^{4}$

The global prevalence of diabetic foot ulcers (DFU) varies from $3 \%$ to $13 \%$ worldwide, with a global average of $6.4 \% .^{5}$ The annual incidence of DFU in diabetic patients is known to be about $2 \%$ to $5 \%$ and the lifetime risk ranges from $15 \%$ to $25 \% .{ }^{1,6,7}$ More than half of all DFU become infected, and diabetic foot infections (DFIs) lead to higher amputation rates in the diabetes population. ${ }^{8}$ It is generally known that DFU is a leading cause of nontraumatic lower extremity amputations. ${ }^{9}$ A recent prospective cohort study followed up the patients with neuropathic DFU (nDFU) for 14 years to compare the amputation and mortality to patients without DFU. It showed that $29.3 \%$ patients with nDFU had limb amputations. The 5- and 10year mortality was $22 \%$ and $71 \%$ in the DFU group with a median survival of 7.72 years compared to $3 \%$ and $5 \%$ and survival of 12.6 years in nDFU group. ${ }^{10}$ Peripheral arterial disease (PAD) like cardiovascular disease, is a major arterial disease caused by atherosclerosis, which is associated with a 20 -fold higher prevalence in patients with diabetes and it is known to be a risk factor for the highest severity of single factors in diabetic patients, the probability of amputation within one year after the first ulcer is $34.1 \%$ and the mortality rate has been reported to be $5.5 \% .{ }^{11}$ The risk of death at 5 years for a patient with a DFU is 2.5 times as high as the risk for a patient with diabetes who has no foot ulcer. ${ }^{12}$ There were studies reported that the 5-year survival rate in major lower extremity amputation in the diabetes population is estimated at less than $50 \%{ }^{13}$

Consequently, DFU leads to decreased quality of life and increased financial costs, morbidity, and even mortality in the diabetes population. Surprisingly, the cost of DFU has been reported to be higher than the cost of treatment for many types of cancer. ${ }^{1}$ Therefore, DFU remains a serious public health problem. Nevertheless, the incidence of diabetes and its complications vary in different regions, and the methods of care and treatment vary depending upon the locality, inevitably resulting in different costs of treatment. In the study, we reported DFU patients' total costs of the wound and vascular disease treatment center of Tianjin (China) in the past 7 years. The study mainly aims was to analyze total cost and length of stay for patients with DFU and researched the possible correlation factors, such as age, gender, amputation or not, with or without PAD, etc. Through analyzing large sample data of DFU patients, we gained insight into variation in the economic burden of the condition and socioeconomic characteristics, which may provide a useful basis for future health economic studies and management of DFU.

\section{Materials and Methods}

In this retrospective analysis, we extracted the data of DFU patients discharged from 2 April 2013 to 8 July 2020 in the Electronic Medical Record (EMR) system of the First Teaching Hospital of Tianjin University of Traditional Chinese Medicine (TCM). The homepage of the EMR system was queried using the national clinical version 2.0 disease diagnosis code (ICD10), the data of patient's basic information were exported, including patient's ID, gender, age, length of stay, various hospitalization costs, surgical information, amputation rate, comorbidity (PAD), etc. The hospital discharge diagnostic code E14.500x050 was defined as inclusion criteria, namely the diagnosis of DFU, and all information and data records of patients should be complete and correct. The codes related to the diagnosis of diabetic foot we searched also include: E14.500x041, E14.500x042, E14.500x043, E14.500x044, E14.700x031, E14.700x032, E11.700x031, E11.700x032, E11.500x050, E11.500x021+I79, E11.500 $\mathrm{x} 043, \mathrm{E} 11.500 \mathrm{x} 044, \mathrm{E} 11.504, \mathrm{E} 11.505$, all of which except any pressure ulcers.

The data were subjected to frequency analysis, to obtain the baseline characteristics of all patients. Total cost, inspection cost, drug cost, surgery cost, and length of stay were calculated and described to analyze the trends of these variables from 2014 to 2020. The drug and inspection costs included all the costs of initial evaluation, diagnosis and treatment of DFU and other co-morbidity or underlying diseases. The surgery cost included expenses of amputation, debridement, angioplasty, balloon expansion, stent placement, etc. The descriptive results were shown as the frequency. For the continuous variables, the means and standard deviations or median and quartile were calculated. The chi-square test was used to compare the differences between the categorical variables. Linear regression was used for correlation analysis of continuous variables. Such as among total cost other costs (drug cost, inspection cost, surgery cost) and length of stay. The correlation analysis between the length of stay and gender, amputation was also conducted. The differences by year or age were compared by one-way ANOVA (Test F) for the length of stay with a normal distribution. Kruskal-Wallis test was 
used to compare multi-group continuous variables (hospital costs) with the non-normal distribution. Two independent sample $t$-test was used to compare the difference between gender and amputation on length of stay, and logistic regression analysis was used to calculate odds ratio (OR) and corresponding 95\% CIs, and to estimate the effect of amputation risk factors, including age and PAD.

The data exported from the EMR system were analyzed statistically and received in the form of Microsoft Excel 2007 files. Then, the statistical analysis was conducted by using IBM SPSS v.21 statistical software, and the figure was drawn with GraphPad Prism v.8 graphics software. The threshold of statistical significance was set at $\mathrm{P}<0.05$.

\section{Results}

According to the retrieval strategy and inclusion criteria, the discharged patients diagnosed as a diabetic foot from 2 May 2013 to 8 July 2020 were retrieved in the EMR system. All the patients included in the study were diagnosed with DFU, the patients with incomplete information records and missing data were excluded. Finally, 3654 patients were included in the analysis. The patient's discharge date was from 28 February 2014 to 8 July 2020 (Figure 1).

\section{Patient Demographic Characteristics and Admissions}

Overall, 3654 patients were analyzed in the study (mean age, $66.73 \pm 11.02$ years, $67.5 \%$ male, $32.5 \%$ Female, $\mathrm{P}>$ $0.05)$, the average total hospital cost, drug cost, inspection cost, surgery cost, and length of stay per patient adjusted changed significantly over time from 2014 to 2020. In these cases, there were significant statistical differences in the amputation rate and the percentage of PAD in different years $(\mathrm{P}<0.05$; Table 1$)$.

\section{The Trend of Total Hospitalization Cost}

By year groups, the average total hospital cost ranged from $¥ 15,535.58$ by 2014 to $¥ 42,040.60$ by 2020 . The figure showed that this growth trend was more remarkable from 2017 to 2020 ( $<<0.05$; Figure 2 ). In this study, the average drug cost, inspection cost, and surgery cost per patient were counted. The tendency of drug cost change was from $¥ 7793.07$ to $¥ 9985.37$, inspection cost from $¥ 2138.06$ to $¥ 2663.32$ and surgery cost from $¥ 1225.67$ to $¥ 1382.07$ ( $\mathrm{P}<0.05$; Figure 2). Furthermore, the correlation test was performed to assess a possible linear association between these three variables and the total cost. The results showed that these variables were directly related (Figure 3). Specifically, drug cost vs total cost and

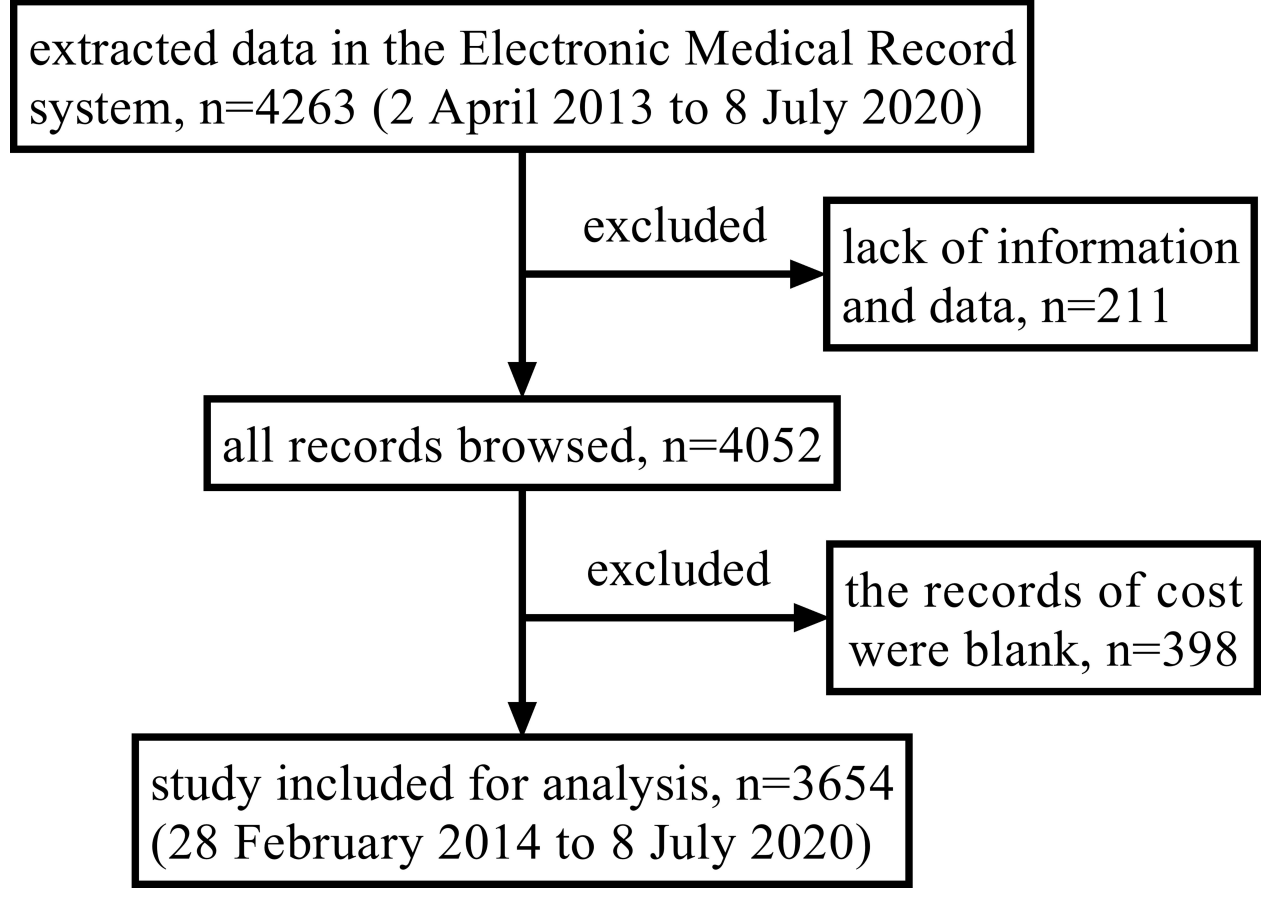

Figure I Flow diagram of the study selection process. 
Table I Patient Demographic Characteristic and the Average Cost per Person (in 2020 China, RMB)

\begin{tabular}{|c|c|c|c|c|c|c|c|c|c|}
\hline \multirow{2}{*}{$\begin{array}{l}\text { Patient } \\
\text { Demographic } \\
\text { Characteristic }\end{array}$} & \multicolumn{7}{|l|}{ Year } & \multirow[t]{2}{*}{ Total } & \multirow[t]{2}{*}{ P-value } \\
\hline & 2014 & 2015 & 2016 & 2017 & 2018 & 2019 & 2020 & & \\
\hline Cases (N) & 499 & 571 & 576 & 873 & 580 & 442 & 113 & 3654 & \\
\hline $\begin{array}{l}\text { Age, years (M士SD) } \\
<45 \\
46-55 \\
56-65 \\
66-75 \\
76-85 \\
>85\end{array}$ & $\begin{array}{l}67.73 \pm 10.64 \\
9 \\
53 \\
138 \\
181 \\
100 \\
18\end{array}$ & $\begin{array}{l}66.68 \pm 9.59 \\
15 \\
44 \\
184 \\
225 \\
98 \\
5\end{array}$ & $\begin{array}{l}66.59 \pm 10.75 \\
20 \\
64 \\
189 \\
170 \\
113 \\
20\end{array}$ & $\begin{array}{l}66.35 \pm 11.39 \\
43 \\
73 \\
302 \\
282 \\
128 \\
45\end{array}$ & $\begin{array}{l}66.96 \pm 11.52 \\
28 \\
75 \\
140 \\
201 \\
112 \\
24\end{array}$ & $\begin{array}{l}66.95 \pm 11.88 \\
24 \\
40 \\
121 \\
155 \\
83 \\
19\end{array}$ & $\begin{array}{l}64.24 \pm 11.52 \\
11 \\
9 \\
41 \\
37 \\
15 \\
0\end{array}$ & $\begin{array}{l}66.73 \pm 11.02 \\
150(4.1) \\
358(9.8) \\
1115(30.5) \\
1251(34.2) \\
649(17.8) \\
131(3.6)\end{array}$ & 0.076 \\
\hline $\begin{array}{c}\text { Gender } \\
\text { Female } \\
\text { Male }\end{array}$ & $\begin{array}{l}157 \\
342\end{array}$ & $\begin{array}{l}206 \\
365\end{array}$ & $\begin{array}{l}185 \\
391\end{array}$ & $\begin{array}{l}289 \\
584\end{array}$ & $\begin{array}{l}171 \\
409\end{array}$ & $\begin{array}{l}148 \\
294\end{array}$ & $\begin{array}{l}30 \\
83\end{array}$ & $\begin{array}{l}1186(32.5) \\
2468(67.5)\end{array}$ & 0.225 \\
\hline $\begin{array}{l}\text { Per patient cost }(\mathbf{¥}) \\
\text { Total cost } \\
\text { Drug cost } \\
\text { Inspection cost } \\
\text { Surgery cost }\end{array}$ & $\begin{array}{l}15,535.58 \\
7793.07 \\
2138.06 \\
1225.67\end{array}$ & $\begin{array}{l}20,089.29 \\
9995.83 \\
2664.21 \\
1483.55\end{array}$ & $\begin{array}{l}19,294.72 \\
9820.87 \\
2399.79 \\
822.15\end{array}$ & $\begin{array}{l}16,074.99 \\
8100.68 \\
1840.16 \\
856.88\end{array}$ & $\begin{array}{l}26,685.84 \\
12,273.10 \\
3021.17 \\
1660.11\end{array}$ & $\begin{array}{l}34,291.13 \\
12,593.08 \\
4209.37 \\
2584.17\end{array}$ & $\begin{array}{l}42,040.60 \\
13,070.25 \\
4796.87 \\
2342.30\end{array}$ & $\begin{array}{l}21,826.91 \\
9985.37 \\
2663.32 \\
1382.07\end{array}$ & $<0.05$ \\
\hline $\begin{array}{l}\text { Length of stay, days } \\
(M \pm S D)\end{array}$ & $14.29 \pm 7.42$ & $|5.9 \pm 9.7|$ & $|5.7| \pm 7.9 \mid$ & $14.88 \pm 7.77$ & $22.2 \pm 17.07$ & $25.7 \pm 20.43$ & $31.4 \pm 25.00$ & $18.10 \pm 13.55$ & $<0.05$ \\
\hline $\begin{array}{l}\text { Amputation, N (\%) } \\
\text { Yes } \\
\text { No }\end{array}$ & $\begin{array}{l}46(9.2) \\
453(90.8)\end{array}$ & $\begin{array}{l}38(6.7) \\
533(93.3)\end{array}$ & $\begin{array}{l}51(8.9) \\
525(91.1)\end{array}$ & $\begin{array}{l}58(6.6) \\
815(93.4)\end{array}$ & $\begin{array}{l}73(12.6) \\
507(87.4)\end{array}$ & $\begin{array}{l}68(I 5.4) \\
374(84.6)\end{array}$ & $\begin{array}{l}29(25.7) \\
84(74.3)\end{array}$ & $\begin{array}{l}363(9.9) \\
3291(90.1)\end{array}$ & $<0.05$ \\
\hline $\begin{array}{l}\text { PAD, N (\%) } \\
\text { Yes } \\
\text { No }\end{array}$ & $\begin{array}{l}436(87.4) \\
63(12.6)\end{array}$ & $\begin{array}{l}428(75.0) \\
143(25.0)\end{array}$ & $\begin{array}{l}467(81.1) \\
109(18.9)\end{array}$ & $\begin{array}{l}725(83.0) \\
148(17.0)\end{array}$ & $\begin{array}{l}473(81.6) \\
107(18.4)\end{array}$ & $\begin{array}{l}369(83.5) \\
73(16.5)\end{array}$ & $\begin{array}{l}96(85.0) \\
17(15.0)\end{array}$ & $\begin{array}{l}2994(81.9) \\
660(18.1)\end{array}$ & $<0.05$ \\
\hline
\end{tabular}

Abbreviations: $M \pm S D$, mean \pm standard deviation; $P A D$, peripheral arterial disease.

inspection cost vs total cost had high positive correlation ( $\mathrm{r}$ $=0.858,0.754 ; \mathrm{P}<0.05)$, surgery cost vs total cost had a moderate positive correlation $(\mathrm{r}=0.585 ; \mathrm{P}<0.05)$. The increase of these three costs accounted for a high proportion of the total cost growth.

By age groups, two age groups with the highest number of admissions were patients aged 56-65 years $(\mathrm{n}=$ $1115)$ and $66-75$ years $(n=1251)$. However, the highest average cost was produced by the patients aged $>85$ years ( $\mathrm{n}=131$ ), mean at $¥ 29,255.15$, median at $¥ 17,082.60$, followed by those aged $76-85$ years, with mean at $¥ 23,719.15$, median at $¥ 18,125.55$. The lowest average cost corresponded to those aged 56-65 years $(n=1115)$, mean at $¥ 20,725.60$, median at $¥ 15,728.38$. Furthermore, the mean cost by patient age groups presented statistically significant differences $\left(\chi^{2}=19.70, d f=5, \mathrm{P}=0.001\right)$. Paired comparison of mean cost by age groups showed that aged 56-65 years vs aged 76-85 years, aged 56-65 years vs aged $>85$ years, aged $66-75$ years vs aged $76-85$ years and aged $66-75$ years vs aged $>85$ years had statistically significant differences $(P=0.026,0.026,0.034$, 0.031; Figure 4, Table 2). By amputation and PAD groups, the cost of amputation patients (median at $¥ 36,441.80$, quartile range at $¥ 24,271.25$ ) was significantly higher than without amputation (median at $¥ 14,943.41$, quartile range at $¥ 17,581.42),(\mathrm{P}<0.05$; Figure 5, Table 3$)$, and with PAD (median at $¥ 16,482.63$, quartile range at $¥$ 20,410.32) was significantly higher than without PAD (median at $¥ 15,290.50$, quartile range at $¥ 18,566.59$ ), $(\mathrm{P}<0.05$; Figure 6, Table 4).

\section{Length of Stay (Days)}

Similarly, by year groups, the average length of stay ranged from 14.29 days (SD 7.42) by 2014 to 31.4 days (SD $25.00)$ by $2020(\mathrm{P}<0.05$; Figure 7$)$. During the seven years analyzed, all hospital admissions of patients with DFU were recorded, with a mean of 18.1 days (SD 13.55) per case attended. The relationship between the 


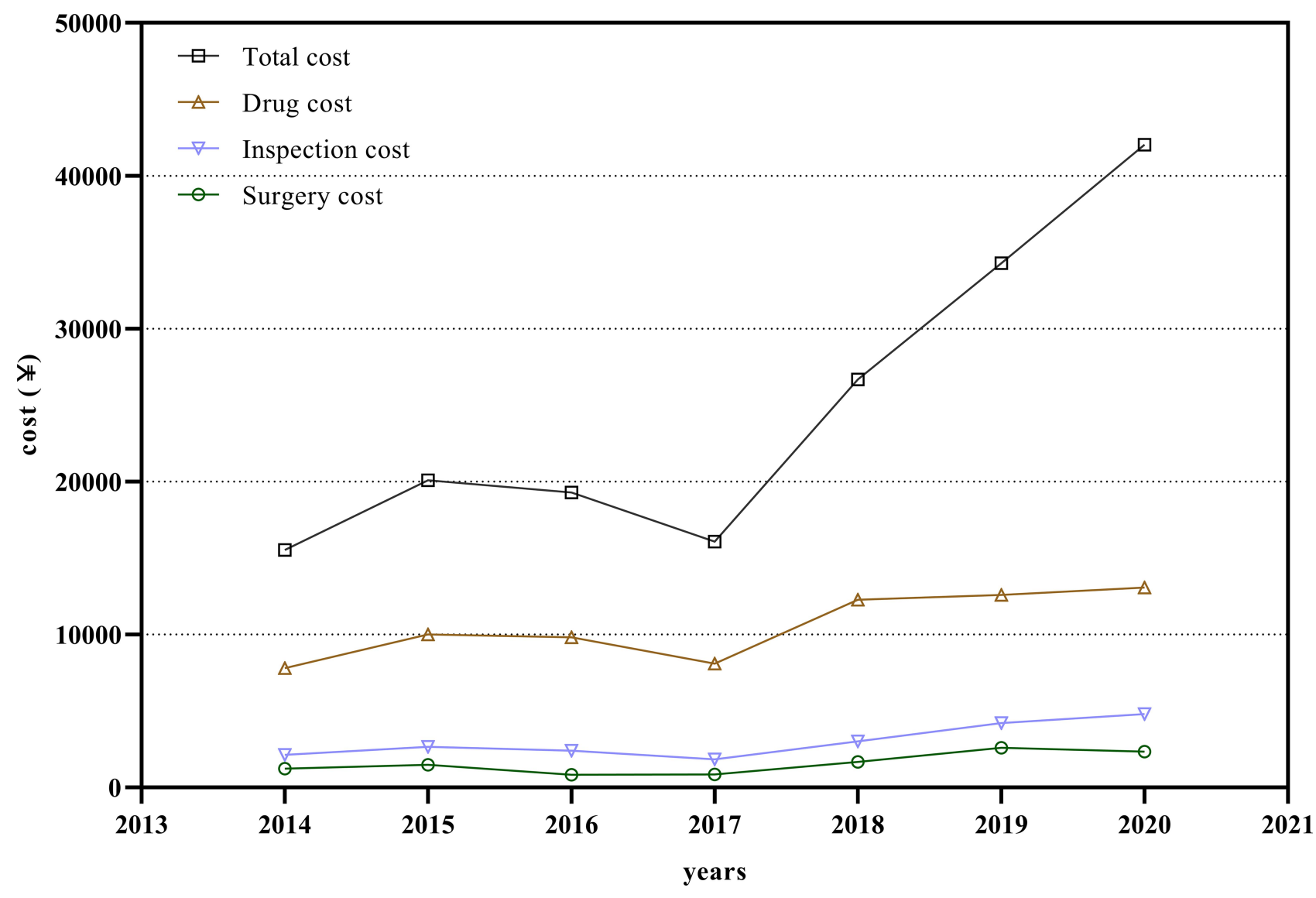

Figure 2 The average total cost, drug cost, inspection cost, and surgery cost per patient, by year groups.

total cost and the length of stay was analyzed by a linear relationship (Figure 8), the equation is as follows: $\mathrm{Y}=$ $1253 \mathrm{X}-850.4\left(\mathrm{R}^{2}=0.567\right)$.

There were 2468 male patients and 1186 female patients included in the study $(\mathrm{P}>0.05)$. The average stay was evenly matched between the gender, at 18.44 days (SD 13.57), and 17.38 days (SD 13.48) for male and female patients, respectively, the ANOVA revealed significant difference $(\mathrm{F}=4.90, \mathrm{P}<0.05$, Figure 9, Table 5).

Regarding the annual incidence of amputation of DFU patients from $9.2 \%$ of 2014 to $25.7 \%$ of 2020 (P<0.05), showed a remarkable increase over seven years and the overall prevalence was $9.9 \%(n=363)$. Besides, the average length of stay was compared between the amputation group and non-amputation group. The average length of stay in the amputation group was 32.76 days (SD 19.25) and in the non-amputation group was 16.48 days (SD 11.69) $(\mathrm{P}<0.05$; Figure 10, Table 6).

In this study, the influence of age and PAD on the amputation rate was analyzed. The results exhibited that the average incidence of PAD in DFU patients admitted to our center was as high as $81.9 \%(n=2994)$. Logistic regression analysis showed that the risk of amputation in DFU patients with PAD was 3.46 times higher than without PAD (OR: 3.46, 95\% CI: $1.33 \sim 9.01$; $\mathrm{P}<0.05$; Figure 11). In addition, amputation risk was significantly increased in patients with age $>85$ (OR: 3.34, 95\% CI: $2.20 \sim 5.07$; $\mathrm{P}<0.05$; Figure 11).

\section{Discussion}

Because of the increasing prevalence of this disease, the current socioeconomic burden of care and treatment for affected patients is significant. The Medicare spending for DFU was estimated to be more than $\$ 1.45$ billion annually according to the 1995 Medicare data in America. ${ }^{14}$ The hospital costs are rising and ranging anywhere from $\$ 3000$ to $\$ 108,000$ per ulcer depending on the extent and management of the disease. ${ }^{15,16}$ In recent years, more and more studies on the management and treatment costs of the diabetic foot have been carried out. But the conclusions of different regions about describing recent trends in hospital costs over time are different, and large sample 

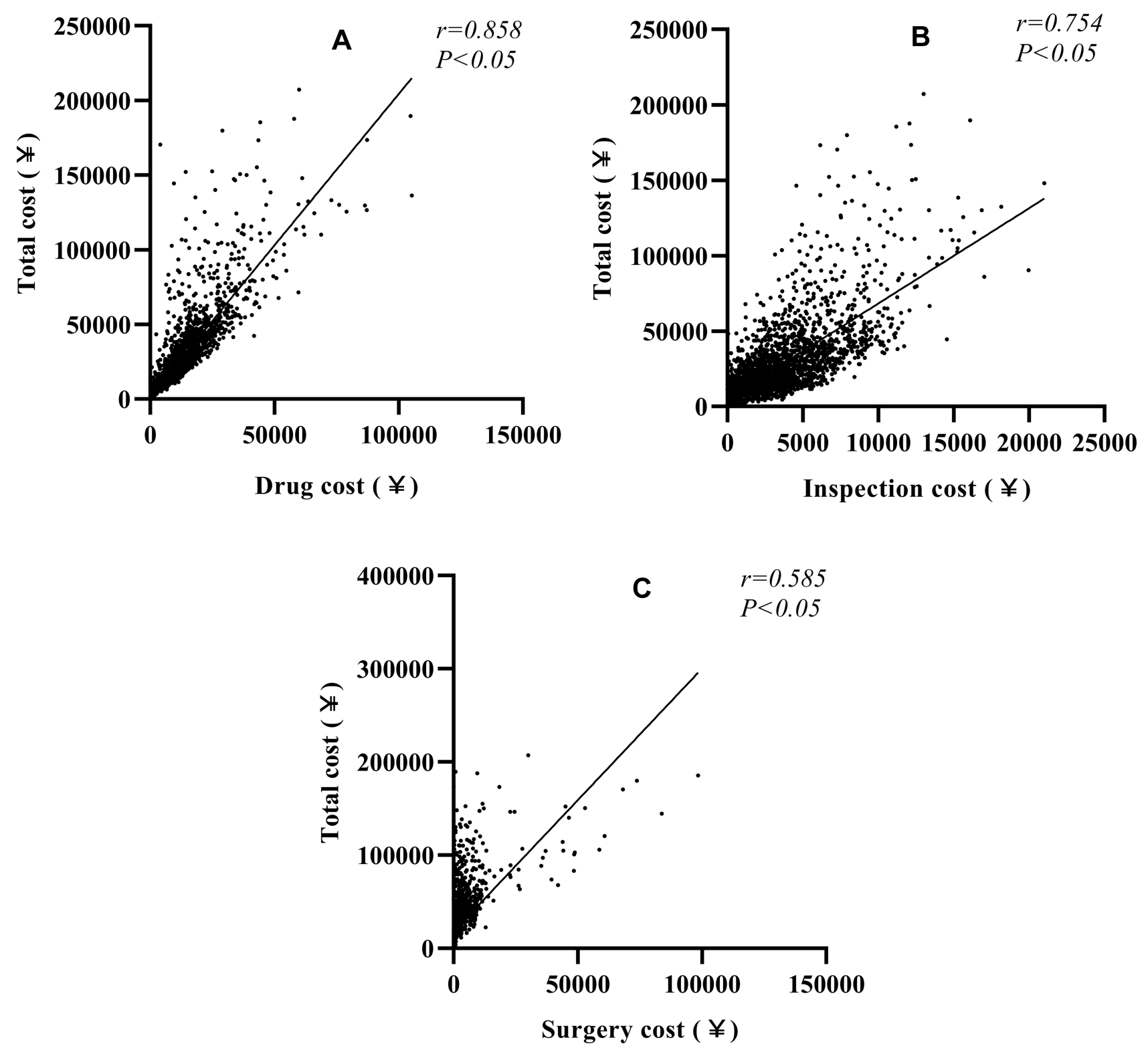

Figure 3 Correlation test. Spearman correlation coefficient. r: $0.90-1.00$, very high positive correlation. r: $0.70-0.90$, high positive correlation; r: $0.50-0.70$, moderate positive correlation; $r$ : $0.00-0.30$, negligible correlation. (A) Drug cost vs total cost; (B) inspection cost vs total cost; (C) surgery cost vs total cost.

studies of socioeconomic research on DFU treatment are rare in China. This study aimed to evaluate the cost of diabetic foot and length of stay and allowed a rational comparison of the economic burden of diabetic foot in different years to be conducted. Furthermore, potential correlation factors for rising total hospital costs and length of stay among patients with diabetic foot ulcers were investigated from 2014 to 2020.

Our analysis showed that an average of total cost ranged from $¥ 15,535.58$ by 2014 to $¥ 42,040.60$ by 2020 , especially from 2017 to 2020, the growth trend was more significant. However, the Eurodiale study estimated the average cost of a patient to be between $€ 7147$ and $€ 18,790$, this figure increased to $€ 24,540$ if the patient was treated by amputation. ${ }^{17}$ In the United States, corresponding values of $\$ 5500$ and $\$ 28,000$ per patient per year have been reported. ${ }^{18}$ Habacher estimated the basic treatment cost for diabetic ulcers to be $€ 1171$ for outpatients, rising to $€ 7844$ for more complex cases requiring hospitalization. ${ }^{19}$ The hospitalization cost of our treatment center is increasing year by year, but the overall cost is less than that of European and American countries. Moreover, this study found that the growth of total cost had a strong positive correlation with the increase in the cost of drug, 


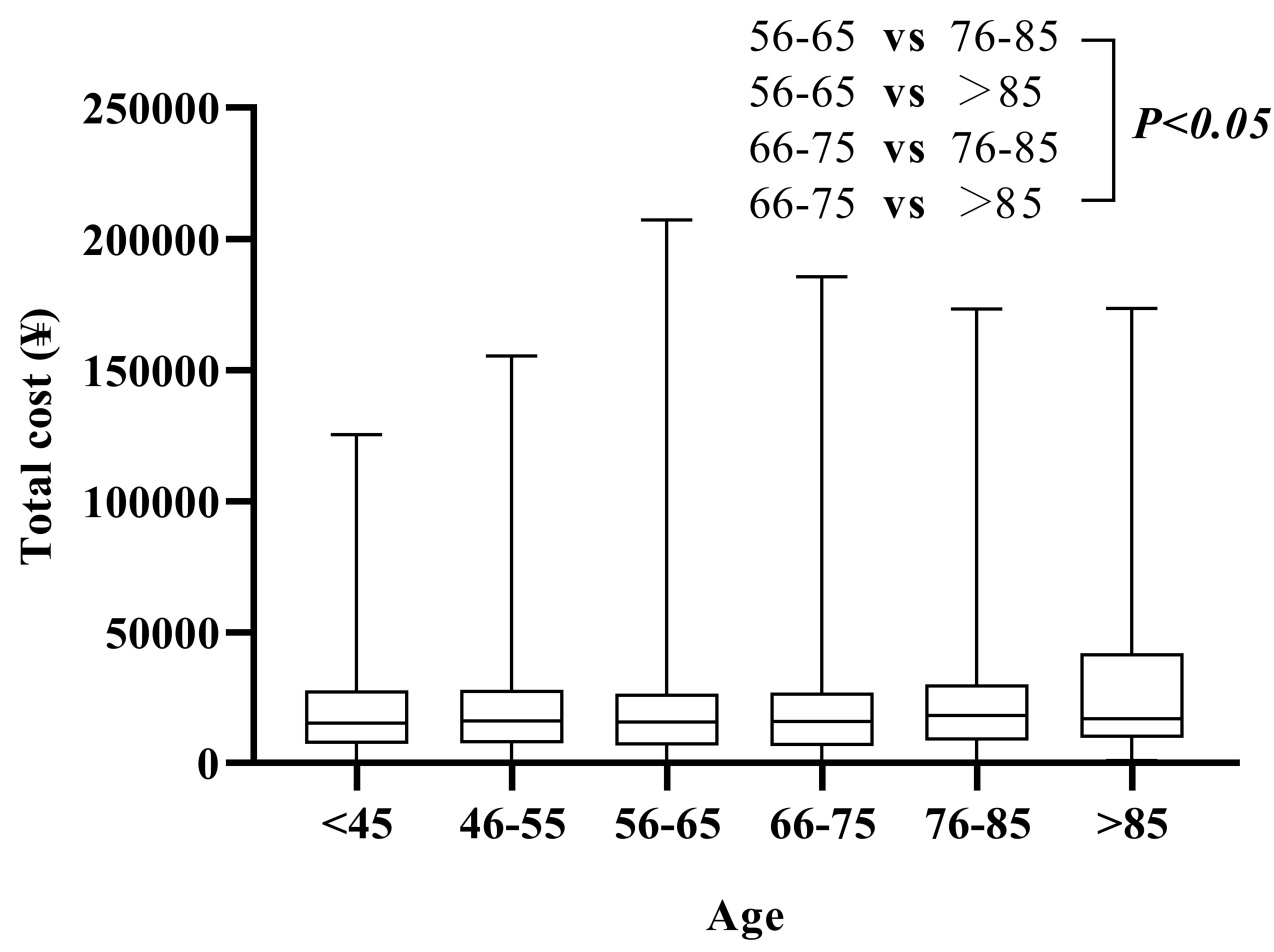

Figure 4 Total cost by age groups.

inspection, and surgery, which were often related to the prolonged length of stay of patients with DFU, increased comorbidities, and comprehensive treatment of various diseases throughout the body. Furthermore, such a cost increase might be due to the development of medications and dressing materials. Besides, we agree with Joshua and also think that cost correction for inflation and currency conversion account for some of the variance in cost between countries. However, differences in treatment patterns and disease or event definitions are also likely to account for cost differences. ${ }^{20}$

By age groups, the highest number of admissions were patients aged $66-75$ years $(n=1251)$, compared with the study of Pilar in 2018, the main body of hospitalized patients was gradually younger. ${ }^{2}$ In terms of cost comparison, we found that the highest average cost was produced by the patients aged $>85$ years $(\mathrm{n}=131)$, mean at $¥ 29,255.15$, median at $¥ 17,082.60$. Pilar’s result was 55-59 years $(\mathrm{n}=282)$, at $€ 8059$. A paired comparison of mean costs by age group had statistically significant differences in our study $(\mathrm{P}=0.001)$. Nevertheless, the latter did not present statistically significant differences $(\mathrm{P}=$ 0.294). By amputation and PAD groups in the study, the total cost of patients with amputation and PAD were significantly higher than without amputation and PAD. We agreed with the conclusions and views that information about the epidemiology of amputation and PAD associated with DFU were likely to be crucial for predicting future disease progression and establishing a health-care budget. $^{21}$

During the seven years analyzed, all hospital admissions of patients with DFU were recorded, with a mean of 18.1 days (SD 13.55) per case attended. In a Europe-wide study, the corresponding rate has been estimated at 23 days. $^{22}$ A previous study carried out that the average hospital stay for these patients was 11 days in the Moral Meseguer Hospital (Murcia, Spain), which finding was in line with Joshua's study. ${ }^{20,23}$ In addition, our study

Table 2 Total Cost by Age Groups

\begin{tabular}{|l|l|l|l|l|l|l|}
\hline Age & $\mathbf{4 5}$ & $\mathbf{4 6 - 5 5}$ & $\mathbf{5 6 - 6 5}$ & $\mathbf{6 6 - 7 5}$ & $\mathbf{7 6 - 8 5}$ & $\mathbf{8 8 5}$ \\
\hline Mean & 21044.71 & 21463.90 & 20725.60 & 21246.64 & 23719.15 & 29255.15 \\
Median & 15389.63 & 16112.15 & 15728.38 & 15886.06 & 18125.55 & 17082.60 \\
Quartile range & 20400.96 & 20458.08 & 19787.83 & 20369.13 & 21403.10 & 32316.11 \\
\hline
\end{tabular}




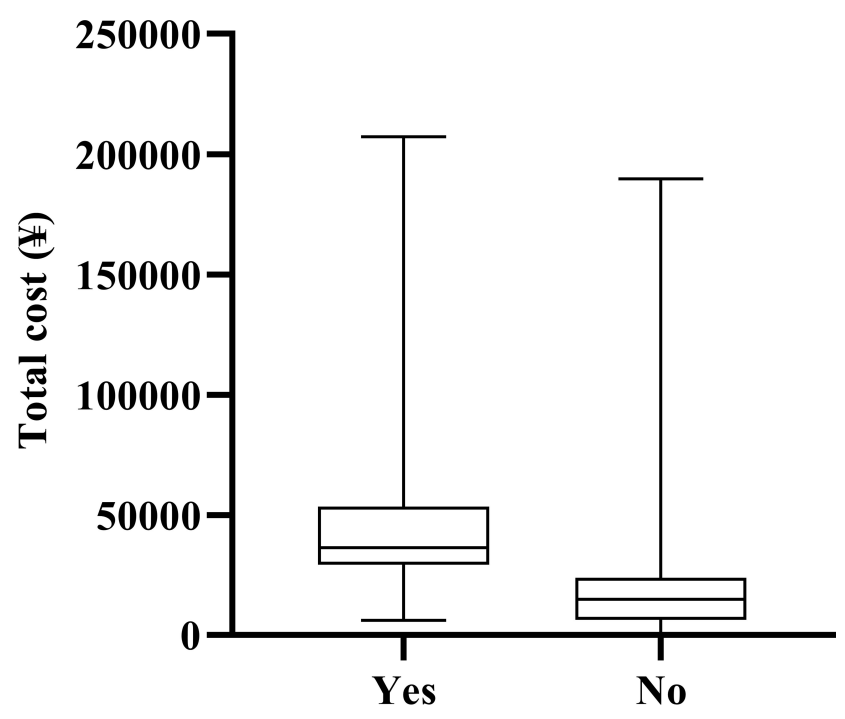

Amputation

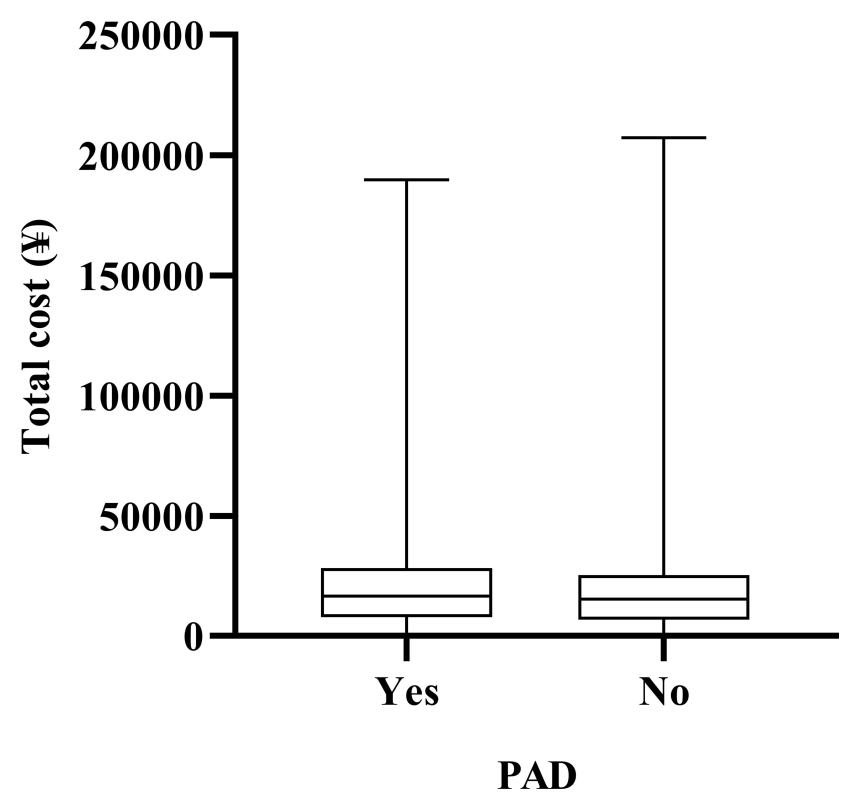

Figure 6 Total cost by PAD groups.

that the total cost comparison was no significant difference by gender groups (mean \pm SD: $¥ 22,161.19 \pm ¥ 22,592.78$ vs $¥ 21,131.28 \pm ¥ 22,447.83, \mathrm{P}=0.196$ ). While Caitlin’s research revealed that the total cost of the male was more than females between 2005 and 2010 ( $\mathrm{P}<0.05$ ). Besides, the average length of stay was compared between the amputation group and non-amputation group. The average length of stay (days) in the amputation group was longer than non-amputation group (mean $\pm \mathrm{SD}: 16.48 \pm 11.69$ vs $32.76 \pm 19.25, \mathrm{P}<0.05)$. On the other hand, the amputation rate increased significantly, from $9.2 \%$ to $25.7 \%$ in the period from 2014 to 2020 ( $\mathrm{P}<0.05$ ), and the overall prevalence was $9.9 \%$, which was higher than other research reports. For example, Anderson previously reported a relatively stable amputation rate between 1980 and $2000 .^{24}$ Goldberg cited amputation rates ranging between 24.4 and 48.0 per 1000 high-risk diabetic patients within the Medicare population, which was similar to the $4.2 \%$ incidence of major amputations that Caitlin report. ${ }^{25,26}$ The possible reasons for the rapid growth of amputation rate were that most patients with mild diabetic foot often gone to community hospitals, treated in our wound treatment center

Table 3 Total Cost by Amputation Groups

\begin{tabular}{|l|l|l|l|l|}
\hline & Mean & Median & Quartile Range & P-value \\
\hline Amputation & 45951.78 & 36441.80 & 24271.25 & 0.000 \\
$\begin{array}{l}\text { Non- } \\
\text { Amputation }\end{array}$ & 19165.91 & 14943.41 & 17581.42 & \\
\hline
\end{tabular}

Table 4 Total Cost by PAD Groups

\begin{tabular}{|l|l|l|l|l|}
\hline & Mean & Median & Quartile Range & P-value \\
\hline PAD & 21849.75 & 16482.63 & 20410.32 & 0.034 \\
Non-PAD & 21723.29 & 15290.50 & 18566.59 & \\
\hline
\end{tabular}




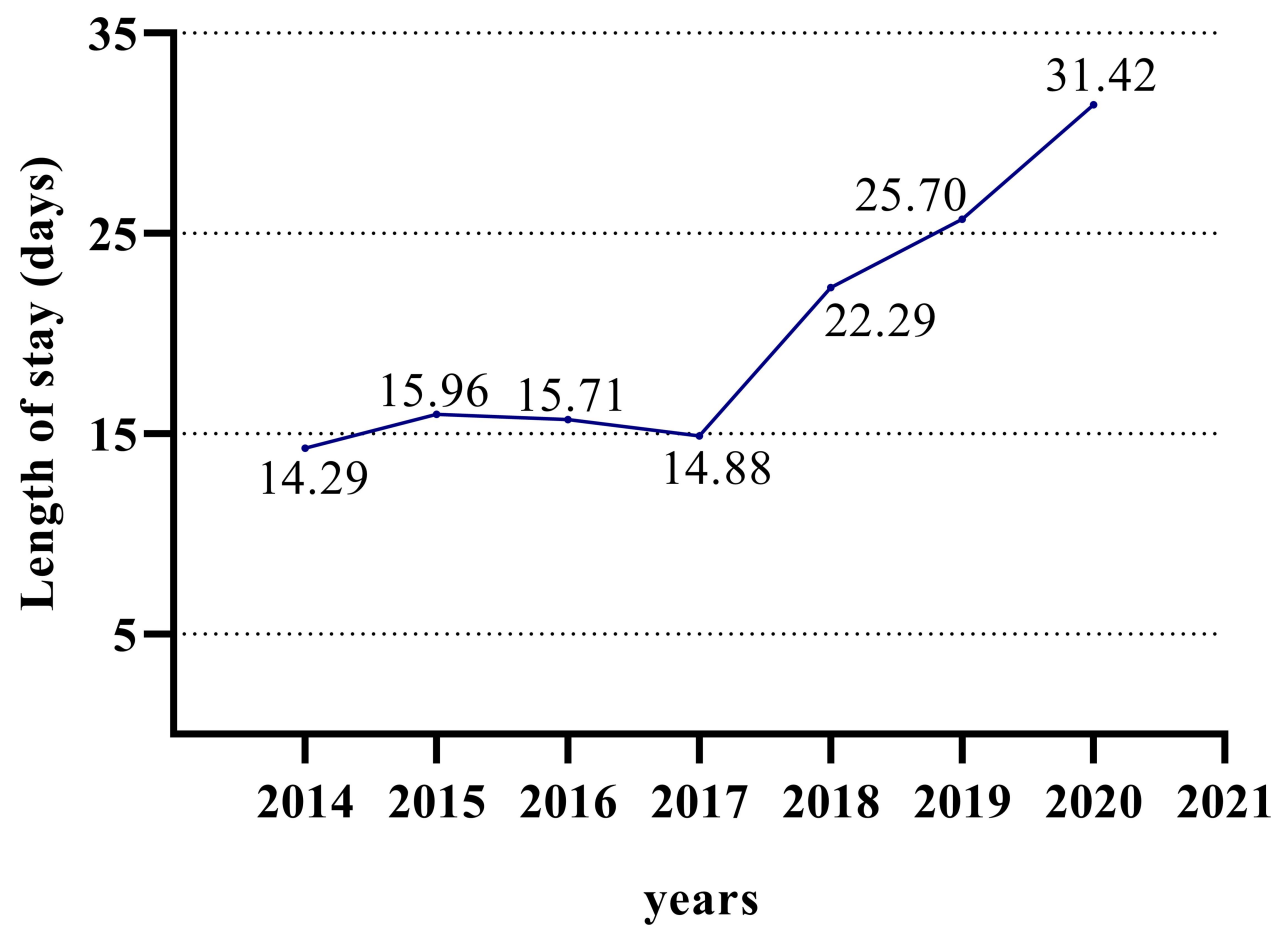

Figure 7 The average length of stay by year groups.

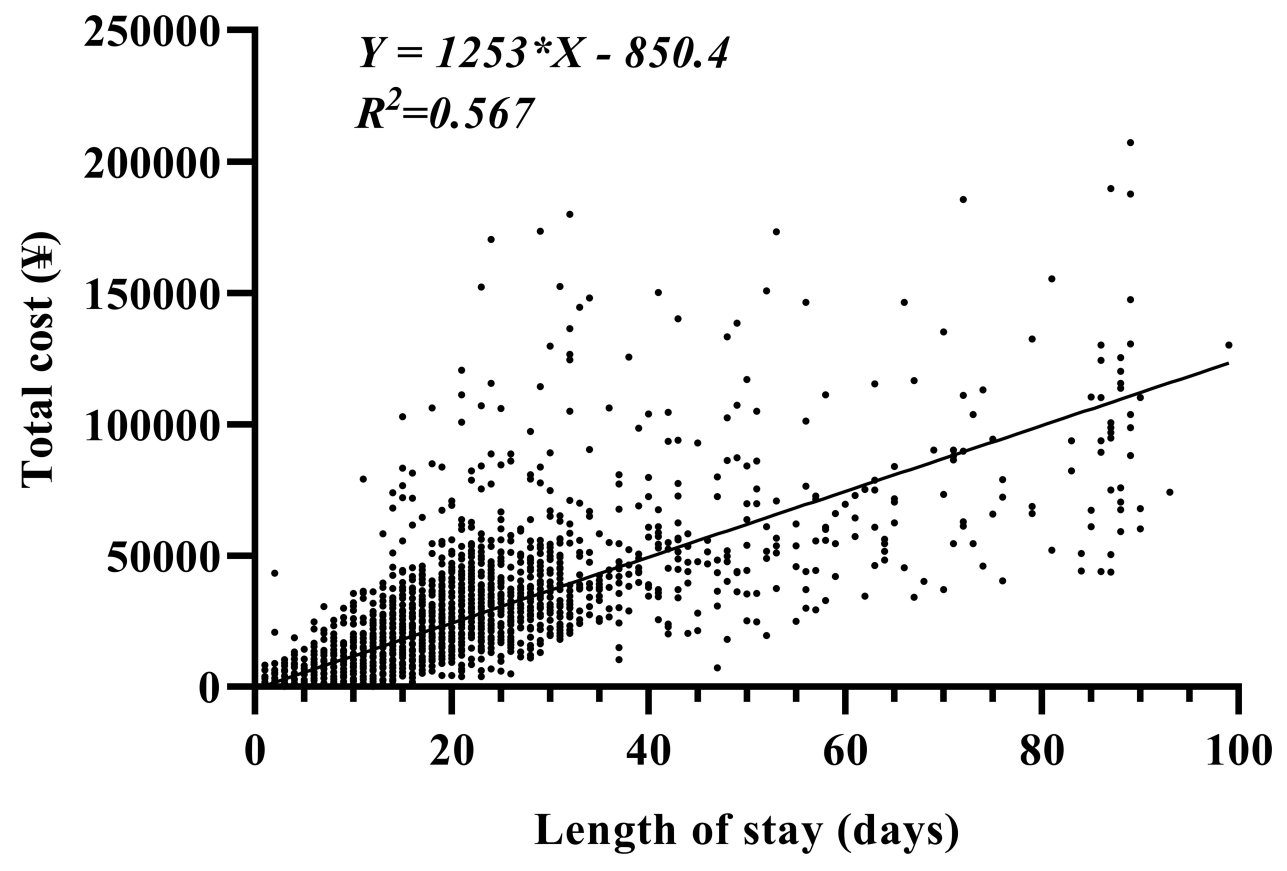

Figure 8 Linear equation between total cost and length of stay.

were more serious, and most of these patients were Wagner grade III or above and combined infection or PAD. In addition, some patients with a long history and multiple hospital admissions could only choose to be amputated at the final stage of DFU.
We found that old age and high incidence of combined PAD were also factors contributing to the increase of amputation risk. When patients age $>85$, amputation risk was significantly increased in our study (OR: 3.34, 95\% CI: 2.20-5.07; $\mathrm{P}<0.05)$. A meta-analysis published in 2019 


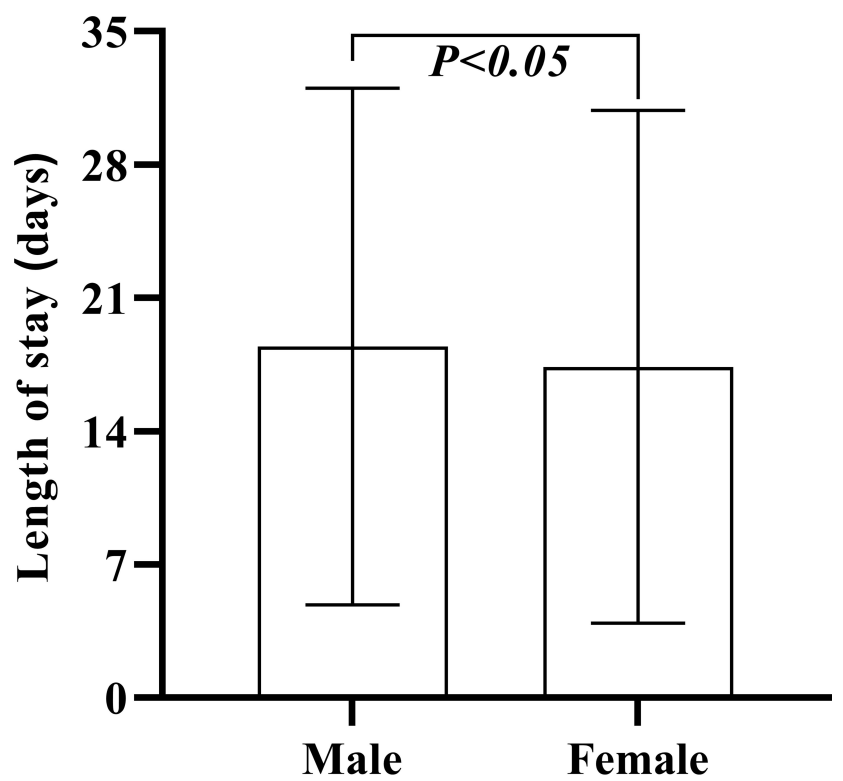

Gender

Figure 9 Length of stay by gender groups.

showed that no significant increase in the risk of amputation was found for the variable of mean age $(\mathrm{P}=0.28),>60$ years of age $(\mathrm{P}=0.42)$, which was not in line with our finding. ${ }^{4} \mathrm{To}$ everyone's surprise, the average incidence of PAD in DFU patients admitted to our center was as high as $81.9 \%$, which made the amputation rate increased significantly (OR: 3.46 , 95\% CI: 1.33-9.01; P < 0.05), and DFU patients with PAD were more likely to be amputated, resulting in increased costs. This also suggested that the amputation rate and the cost pertained to ischemic ulcer. Because in these patients, more inspections and treatments were needed, such as lower extremity angiography, computer tomography angiography (CTA), interventional therapy, etc. It is well known that PAD is a risk factor for the highest severity of single factor and is associated with an increased risk of foot infections. The prevalence of PAD in Europe is increasing, parallel with increasing age and other risk factors for cardiovascular disease. ${ }^{21,27}$ Sayiner conducted multivariate binary logistic regression that significant

Table 5 Length of Stay by Gender Groups

\begin{tabular}{|l|l|l|l|l|l|l|}
\hline & \multirow{2}{*}{ N } & \multirow{2}{*}{ Mean } & SD & \multicolumn{2}{|l|}{$\mathbf{9 5 \%} \mathbf{C l}$} & \multirow{2}{*}{ P-value } \\
\cline { 4 - 6 } & & & & Lower & Upper & \\
\hline Male & 2468 & 18.44 & 13.57 & 17.90 & 18.97 & 0.027 \\
Female & 1186 & 17.38 & 13.48 & 16.61 & 18.15 & \\
Total & 3654 & 18.10 & 13.55 & 17.66 & 18.53 & \\
\hline
\end{tabular}

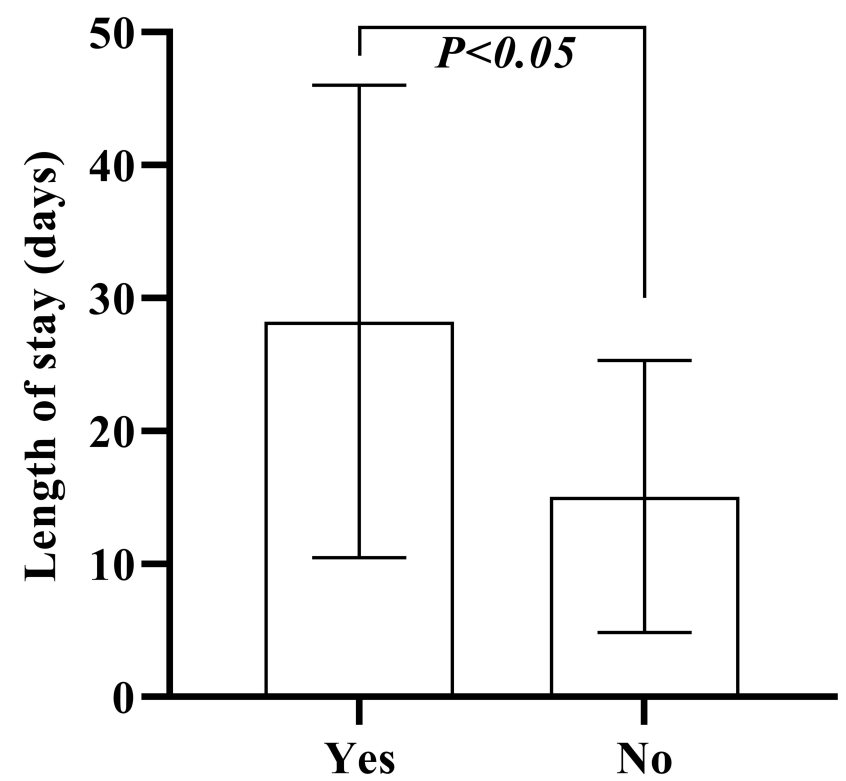

Amputation

Figure 10 Length of stay by amputation and non-amputation groups.

determinants were PAD presence and DFU history. ${ }^{28}$ Gurney meta-analysis revealed PAD was a definite risk factor for amputation in patients with diabetic foot (overall effect: $\mathrm{Z}=$ $2.004, \mathrm{P}=0.045) .{ }^{29}$ We believe that the increase of infection and aggravation of lower limb ischemia may be a main reason for the rising of amputation rate of diabetic foot patients with PAD, which was in line with previous literature that prospectively evaluated 1666 patients over a 2-year period and reported the amputation rate with ischemic infection was greater than that with non-ischemic infection. ${ }^{30}$

This study presented certain limitations. First, there was a selection bias in the included patients because the study was a single-center retrospective review and involved only hospitalized patients and the in-hospital cost, which made a negative impact on representativeness or external validity of our sample. Second, hospitalized patients with a high PAD morbidity of the study tended to be ischemic foot ulcer, but, the degree of ischemia was not

Table 6 Length of Stay by Amputation and Non-Amputation Groups

\begin{tabular}{|l|l|l|l|l|l|l|}
\hline & N & Mean & SD & \multicolumn{2}{|l|}{$95 \%$ Cl } & \multirow{2}{*}{ P-value } \\
\cline { 4 - 6 } & & & & Lower & Upper & \\
\hline Amputation & 363 & 32.76 & 19.25 & 30.77 & 34.74 & 0.000 \\
Non-amputation & 3291 & 16.48 & 11.69 & 16.08 & 16.88 & \\
Total & 3654 & 18.10 & 13.55 & 17.66 & 18.53 & \\
\hline
\end{tabular}




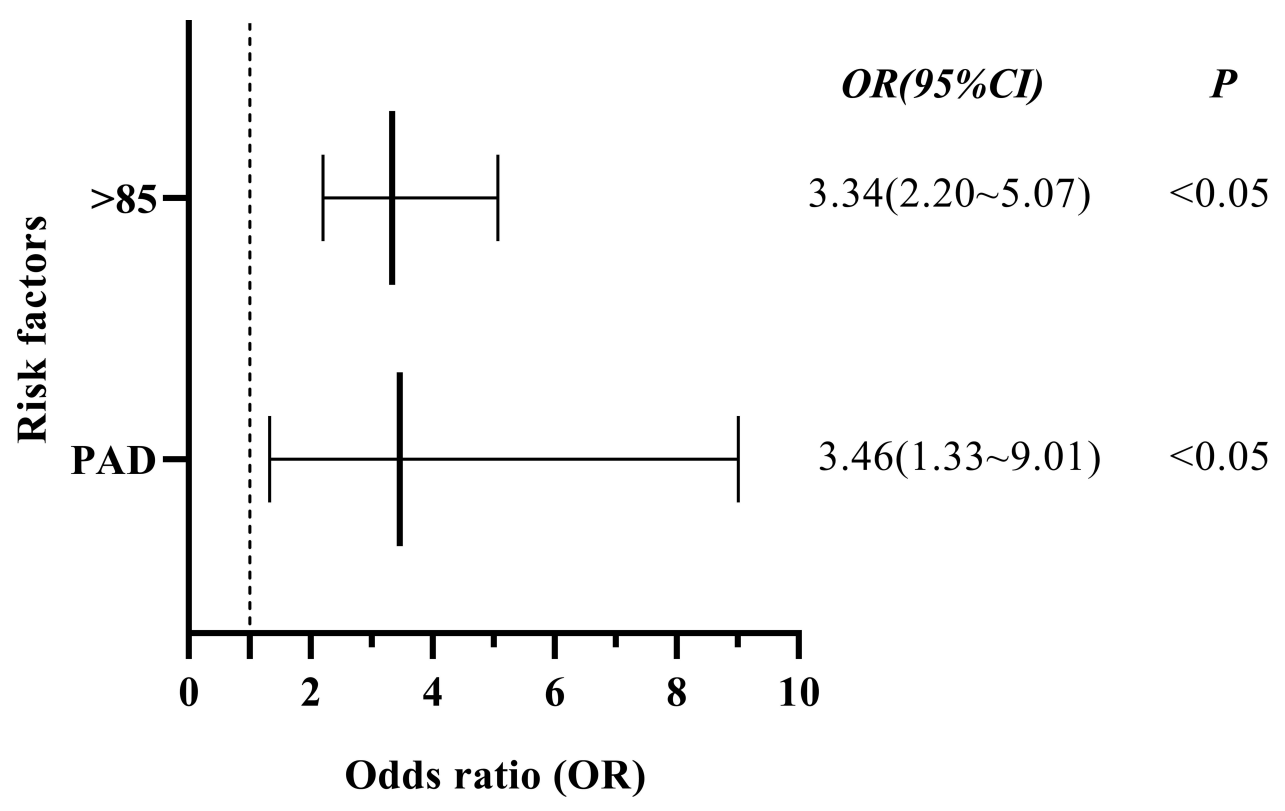

Figure I I Forest plot of amputation risks.

assessed and the exact infection rate of patients with DFU did not be counted due to the limitations of research method. Third, since this was an observational study that relied on secondary data from EMRs, it was subject to potential information bias and residual confounding caused by unobserved patient or hospital characteristics. There may be a need for future economic evaluations measuring the accuracy of the costs and resource utilization in the reported values.

\section{Conclusions}

In conclusion, the cost of management for DFU has became a global economic burden. In this study, we demonstrated that the number of hospitalized patients with foot ulcers was relatively stable from 2014 to 2020, but hospital cost and length of stay related to DFU increased significantly over time. The analysis result reflected that old age, male, combine with PAD, and amputation directly or indirectly contributed to the escalating of management cost and length of stay per patient hospitalization with DFU. Up to now, diabetic foot is still a global medical problem, which needs to strengthen the research on social economics. At the same time, education initiative, early prevention strategy, compliance outpatient multidisciplinary care, prevention, and treatment of complications are very important to prevent the situation which is already a huge economic burden.

\section{Ethical Consideration}

Informed verbal consent was required from the patient in the study process, or required from the patient's next of kin because a few patients had passed away. The informed verbal consent process and the study were approved by the ethics committee of First Teaching Hospital of Tianjin University of Traditional Chinese Medicine. We promised that the data of the participants were anonymized or maintained with confidentiality and confirmed that the guidelines outlined in the Declaration of Helsinki were followed.

\section{Author Contributions}

All authors made substantial contributions to conception and design, acquisition of data, or analysis and interpretation of data; All authors took part in drafting the article or revising it critically for important intellectual content and agreed to submit to the current journal; All authors gave final approval of the version to be published and agree to be accountable for all aspects of the work.

\section{Funding}

This research was funded by the National Natural Science Foundation of China (81973854, 81473685) and Ministry of Science and Technology of China (2008BAI53B01, 2008BAI53B011). 


\section{Disclosure}

The authors declare no conflicts of interest.

\section{References}

1. Armstrong DG, Boulton AJM, Bus SA. Diabetic foot ulcers and their recurrence. $N$ Engl $J$ Med. 2017;376:2367-2375. doi:10.1056/ NEJMra1615439

2. Nieto Gil P, Ortega Avila AB, Pardo Rios M, et al. Hospitalisation cost of patients with diabetic foot ulcers in valencia (Spain) in the period 2009-2013: a retrospective descriptive analysis. Int J Environ Res Public Health. 2018;15:1831. doi:10.3390/ijerph15091831

3. Wang J, Zhou Y, Li YP, et al. extensive serum biomarker analysis before and after treatment in healing of diabetic foot ulcers using a cytokine antibody array. Cytokine. 2020;22(133):155173. doi:10. 1016/j.cyto.2020.155173

4. Sen P, Demirdal T, Emir B. Meta-analysis of risk factors for amputation in diabetic foot infections. Diabetes Metab Res Rev. 2019;35: e3165. doi:10.1002/dmrr.3165

5. Jeffcoate WJ, Harding KG. Diabetic foot ulcers. Lancet. 2003;361:1545-1551. doi:10.1016/S0140-6736(03)13169-8

6. Singh N, Armstrong DG, Lipsky BA. Preventing foot ulcers in patients with diabetes. JAMA. 2005;293:217-228. doi:10.1001/ jama.293.2.217

7. IDF Diabetes Atlas, Eighth Edition 2017. International Diabetes Federation. 2018. Available from: http://www.diabetesatlas.org. Accessed October 19, 2020.

8. Prompers L, Huijberts M, Apelqvist J, et al. High prevalence of ischaemia, infection and serious comorbidity in patients with diabetic foot disease in Europe: baseline results from the Eurodiale study. Diabetologia. 2007;50:18-25. doi:10.1007/s00125-006-0491-1

9. Uçkay I, Gariani K, Pataky Z, et al. Diabetic foot infections: state-ofthe-art. Diabetes Obes Metab. 2014;16:305-316. doi:10.1111/ dom. 12190

10. Rastogi A, Goyal G, Kesavan R, et al. Long term outcomes after incident diabetic foot ulcer: multicenter large cohort prospective study (EDI-FOCUS investigators) epidemiology of diabetic foot complications study: epidemiology of diabetic foot complications study. Diabetes Res Clin Pract. 2020;162:108113. doi:10.1016/j. diabres.2020.108113

11. Won SH, Chung CY, Park MS, et al. Risk factors associated with amputation-free survival in patient with diabetic foot ulcers. Yonsei Med J. 2014;55:1373-1378. doi:10.3349/ymj.2014.55.5.1373

12. Walsh JW, Hoffstad OJ, Sullivan MO, et al. Association of diabetic foot ulcer and death in a population-based cohort from the United Kingdom. Diabet Med. 2016;33:1493-1498. doi:10.1111/dme.13054

13. Oh TS, Lee HS, Hong JP. Diabetic foot reconstruction using free flaps increases 5-year-survival rate. J Plast Reconstr Aesthet Surg. 2013;66:243-250. doi:10.1016/j.bjps.2012.09.024

14. Harrington C, Zagari MJ, Corea J, et al. A cost analysis of diabetic lower-extremity ulcers. Diabetes Care. 2000;23:1333-1338. doi:10.2337/diacare.23.9.1333
15. Cavanagh $\mathrm{P}$, Attinger $\mathrm{C}, \mathrm{Abbas} \mathrm{Z}$, et al. Cost of treating diabetic foot ulcers in five different countries. Diabetes Metab Res Rev. 2012;28:107-111. doi:10.1002/dmrr.2245

16. Chow I, Lemos EV, Einarson TR. Management and prevention of diabetic foot ulcers and infections: a health economic review. Pharmacoeconomics. 2008;26:1019-1035. doi:10.2165/0019053200826120-00005

17. Prompers L, Huijberts M, Schaper N, et al. Resource utilisation and costs associated with the treatment of diabetic foot ulcers. Prospective data from the Eurodiale study. Diabetologia. 2008;51:1826-1834. doi:10.1007/s00125-008-1089-6

18. Stockl K, Vanderplas A, Tafesse E, et al. Costs of lower-extremity ulcers among patients with diabetes. Diabetes Care. 2004;27:2129-2134. doi:10.2337/diacare.27.9.2129

19. Habacher W, Rakovac I, Görzer E, et al. A model to analyse costs and benefits of intensified diabetic foot care in Austria. $J$ Eval Clin Pract. 2007;13:906-912.

20. Ray JA, Valentine WJ, Secnik K, et al. Review of the cost of diabetes complications in Australia, Canada, France, Germany, Italy and Spain. Curr Med Res Opin. 2005;21:1617-1629. doi:10.1185/03007 9905X65349

21. Chun DI, Kim S, Kim J, et al. Epidemiology and burden of diabetic foot ulcer and peripheral arterial disease in Korea. $J$ Clin Med. 2019;8:748-755. doi: $10.3390 /$ jcm 8050748

22. Jönsson B. Revealing the cost of type II diabetes in Europe. Diabetologia. 2002;45:S5-S12. doi:10.1007/s00125-002-0858-x

23. De Alcalá Martínez D, Aguayo JL, Flores B, et al. Resultados de la hospitalización en pacientes con pie diabético. Cir Españ. 2003;74:92-96. doi:10.1016/S0009-739X(03)72195-2

24. Anderson PL, Gelijns A, Moskowitz A, et al. Understanding trends in inpatient surgical volume: vascular interventions, 1980-2000. J Vasc Surg. 2004;39:1200-1208. doi:10.1016/j.jvs.2004.02.039

25. Goldberg JB, Goodney PP, Cronenwett JL, et al. The effect of risk and race on lower extremity amputations among medicare diabetic patients. J Vasc Surg. 2012;56:1663-1668. doi:10.1016/j.jvs.2012. 05.100

26. Hicks CW, Selvarajah S, Mathioudakis N, et al. Trends and determinants of costs associated with the inpatient care of diabetic foot ulcers. J Vasc Surg. 2014;60:1247-1254. doi:10.1016/j.jvs.2014. 05.009

27. Behrendt CA, Sigvant B, Szeberin Z, et al. International variations in amputation practice: a V ASCUNET report. Eur J Vasc Endovasc Surg. 2018;56:391-399. doi:10.1016/j.ejvs.2018.04.017

28. Sayiner ZA, Can FI, Akarsu E. Patients' clinical characteristics and predictors for diabetic foot amputation. Prim Care Diabetes. 2019;13:247-251. doi:10.1016/j.pcd.2018.12.002

29. Shin JY, Roh SG, Sharaf B, et al. Risk of major limb amputation in diabetic foot ulcer and accompanying disease: a meta-analysis. J Plast Reconstr Aesthet Surg. 2017;70:1681-1688. doi:10.1016/j. bjps.2017.07.015

30. Lavery LA, Armstrong DG, Wunderlich RP, et al. Risk factors for foot infections in individuals with diabetes. Diabetes Care. 2006;29:1288-1293. doi:10.2337/dc05-2425

\section{Publish your work in this journal}

Diabetes, Metabolic Syndrome and Obesity: Targets and Therapy is an international, peer-reviewed open-access journal committed to the rapid publication of the latest laboratory and clinical findings in the fields of diabetes, metabolic syndrome and obesity research. Original research, review, case reports, hypothesis formation, expert opinion and commentaries are all considered for publication. The manuscript management system is completely online and includes a very quick and fair peer-review system, which is all easy to use. Visit http://www.dovepress.com/testimonials.php to read real quotes from published authors. 